\title{
Big Data-driven Value Creation for Organizations
}

\author{
Celina M. Olszak \\ University of Economics in Katowice, Poland \\ celina.olszak@ue.katowice.pl
}

\author{
Jozef Zurada \\ University of Louisville, Louisville, KY, USA \\ WSB Gdansk, Gdansk, Poland \\ jozef.zurada@louisville.edu
}

\begin{abstract}
The past few years have been characterized by an enormous increase in data coming from different sources in real time and in many diverse forms. The term commonly used for such data is Big Data (BD). Much of this BD has a high business value and, if properly utilized, can become an important organizational asset helping the organization to achieve competitive advantage. However, many organizations make a limited use of BD because they lack necessary tools and/or do not understand the value of this data. The main contribution of this study is to investigate an issue of Big Data and elements shaping creation of BD-based business value. In particular, the outcome of this research is to build and verify a framework to provide business value based on BD. The proposed framework is distinguished by three components: (1) dynamic capabilities of organizations, (2) integrated process of $B D$ resource exploration and exploitation, and (3) identification and measurement of business value creation based on $B D$.
\end{abstract}

\section{Introduction}

Many studies show that the competitive position and success of the organization are determined by information resources [7, 13, 37, 39, 54]. Increasingly, however, it is emphasized that the mere possession of information resources is no longer sufficient. Access to information must go in parallel with the organization's capability to analyze it intelligently and create unique values from it $[12,14,26,49]$. The past few years have witnessed the development of large-scale data, referred to as Big Data (BD). Such data mainly come from the Internet, social media, distributed databases and various mobile devices [19, 62]. The huge business potential inherent in BD draws attention of researchers and practitioners. Some studies indicate that the organizations' ability to use BD in decision-making will determine their innovation, competitiveness and survival [18]. Unfortunately, the majority of organizations still use the potential of large-scale data to a limited extent only. This is mainly due to the lack of access to appropriate tools and entire systems aimed at their intelligent analysis and adoption. Moreover, the level of knowledge in organizations about the value of $\mathrm{BD}$ in decision-making is low. There is a lack of strategies, recommendations and guidelines that would be a signpost for the organization, how to capture and derive BD-based value.

The goal of this research is to deepen the knowledge about the nature of BD resources, the value that they can offer to business and the elements that shape the creation of this value. The outcome of the study is the development and initial verification of the BD-driven value creation framework. Three main constructs have been distinguished and characterized in the framework: (1) organization's dynamic capabilities, (2) integrated process of $\mathrm{BD}$ resource exploration and exploitation, and (3) identification and measurement of value.

\section{Applied research method}

This study adopts two research methods. The first research method is the critical assessment of the literature [63] aimed at identifying the most important mechanisms shaping BD-driven value creation. This method is composed of searching for source materials, their selection, as well as their analysis and synthesis. It has been used to develop a comprehensive model of BDdriven value creation. The purpose of the second research method is to initially verify the developed framework. This verification consisted of conducting qualitative research with the use of an in-depth interview in 25 selected organizations.

The search for source materials began with an analysis of the "basket of eight journals" relating to information systems. These are European Journal of Information Systems, Information Systems Journal, Information Systems Research, Journal of AIS, Journal of Management Information Systems, MIS Quarterly, Journal of Strategic Information Systems, and Journal of Information Technology. Additionally, the following specialist journals were explored: Academy of Management Journal, Academy of Management Review, Communications of the ACM, Decision Support Systems, Information Systems Management, Management Decision, MIT Sloan Management Review, and Organization Science. Various conference 
papers and studies from databases such as EBESCO Host, Emerald Management 75, ISI Web of Knowledge, ProQuest, and Scopus were also critically assessed. Over 150 different studies were collected for the initial assessment, which were then singled out based on selected key words, abstracts and titles. Ultimately, 64 papers were classified for an in-depth analysis. As a result of the synthesis of the collected research material, the research gap was identified and a comprehensive framework of BD-driven value creation was proposed.

\section{Big Data concept}

The field of BD is currently regarded as one of the most dynamically developing research areas in the world [7, 11, 30]. The importance of BD potential is noticed both by representatives of academic centers [6, $8,24,27]$ and business practice $[25,33,35,56]$. The mentioned studies claim that the challenge for the coming years and, at the same time, one of the greatest needs of modern organizations is intelligent analytics allowing the discovery of business value from largescale data $[20,31,58]$. The capability to process and use large-scale data is recognized as the main driver of the organization's development, as well as the basis for market survival, innovative success, improved competitiveness and more effective decision-making $[21,46]$.

Although the term BD has recently gained in popularity, there is no consensus on its interpretation. Chen et al. [7] claim that BD represents a broad spectrum of applications and the potential that can be used to create new business opportunities. BD is often associated with a growing amount of real-world data from social media (e.g. Facebook, Twitter, Instragram) and the Internet of Things [22].

Manyika et al. [33] consider that BD refers to databases whose size exceeds traditional databases, and the existing tools for collecting and analyzing such huge volumes of data prove to be insufficient. Some authors $[15,33]$ indicate seven main attributes (7 V's) of BD (Figure 1).

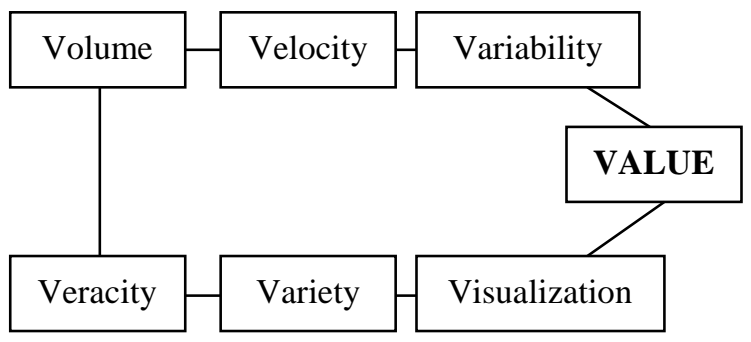

Figure 1. The key BD attributes

These are: (1) Volume - the quantity of data is measured in peta- and zetta-bytes; (2) Velocity - the meteoric speed of data emergence and the need to analyze it in real time; (3) Variety - the heterogenic nature of data that can have different forms (text, images, video, sound, XML) and come from various devices and applications (computers, servers, sensors, mobile devices, Internet, social media); (4) Veracity data can be inconsistent, incomplete and inaccurate; (5) Variability - data are constantly changing; this is particularly evident in the processing of real data and natural language; (6) Visualization - results obtained after BD processing should be presented in a readily accessible and understandable form; (7) Value significant value hidden in data. The last of the attributes refers to the discovery and capture of values flowing from BD analysis. This issue is extremely complex and hardly ever recognized.

The literature cites many of the benefits of using BD $[45,47]$. However, in practice, the vast majority of organizations do not use the BD potential. Such a situation leads to undertaking research, explaining, among others the nature of $\mathrm{BD}$ resources and the mechanisms of BD-driven value creation for business and society as a whole. So far, it has not been possible to develop and verify a comprehensive framework of BD-driven value creation. This issue is the main point of consideration of this study.

\section{Information and ICT-driven value creation}

The question of value, which arises from the philosophical and theological sciences, becomes today of vital importance in business and in times of progressing computerization. The Resource-based View approach (RBV) provides interesting tips on how to create unique values for the organization based on information resources and Informational and Communication Technology (ICT) [17, 40]. In accordance with $\mathrm{RBV}$, certain resource attributes determine the creation of a unique value. These attributes can be classified into two categories [44]: ex ante and ex post. Attributes within the former category refer to resources which are: valuable, rare and appropriately assigned (approprability). The resource is valuable in the context of RBV if it enables the organization to implement a strategy that contributes to improving its efficiency. However, it should be emphasized that resources, which are valuable but also widely available, will not be a source of competitive advantage. Therefore, the rarity, the next attribute, refers to those resources that are not available to all companies. In turn, the appropriation of resources means the ability of organizations to use their potential. Rare and valuable resources, without the capability to use their potential, will not turn into a business value. 
In turn, ex post attributes of information system resources include: difficulty in imitation, nonsubstitutability as well as difficulty in transfer and mobility. These attributes cause that competition has limited possibilities of taking them over and using them. Wade and Hulland [59] state that the difficulty in imitating resources is primarily determined by the company's unique history and the mystery of the processes being carried out. In turn, resources have low substitutability if they are not common and do not have their strategic counterparts (equivalents). Nevertheless, if organizations are able to acquire the resources necessary to imitate the competitive advantage of their rivals, they will gain such advantage, but it will be shortlived. Therefore, the requirement for obtaining a sustainable competitive advantage is that resources are difficult to move, transfer and sell. Technical assets such as hardware and software are relatively easy to acquire and take over. Industrial knowledge, managerial experience as well as other programming and business skills are much more difficult to intercept.

It is worth underlining that some resources are more useful for organizations in a relatively stable environment, while others are more functional in dynamic and unstable conditions. The former are often referred to as key resources, while the latter are dynamic resources. The distinction of these two resources shows the RBV evolution, which in the traditional sense, did not take into account changes taking place in the turbulent environment of the organization. It assumed that the resources are static. Dynamic capabilities are the answer to these challenges. This means that the way the resources are used is at least as important as the strategic valuation of these resources [23, 60]. It is emphasized that the benefits of a given resource pool are transient, which is why organizations must focus on continually acquiring new resources and creating new configurations from them $[2,51,55,64]$.

The issue of value creation was also described in an interesting way by [47]. The authors analyzed ICT from the perspective of various assets. They included human assets (technical skills, business understanding, problem-solving orientation), technological (physical ICT infrastructure, databases, SI architecture, standards) and relations between these assets (customer relationships, management support, risk and responsibility management). In turn, Fenny and Willcocks [16] identified nine key capabilities which are relevant to the development of ICT-based business value that can be captured in four interlocking areas. These are: business and ICT vision, design of ICT architecture, delivery of ICT services and a network of capabilities related to leadership in ICT and acquisition (purchase) of information. Bhardwaj [3], on the other hand, proposed six dimensions of ICT that are important from the point of view of value creation. These are: ICT/business partnership, external links in ICT, ICT strategic thinking, integration of ICT business processes, ICT management and ICT infrastructure.

The research carried out by the authors mentioned above shows that the ICT infrastructure is the easiest asset to intercept and copy by competitors and therefore represents the most "fragile" resource in creating business value. Organizations derive their value mainly from intangible assets, such as new skills, new business models and new products [59].

\section{BD development strategies in organizations}

Many authors highlight that BD can be the source of creating innovative products, services and business opportunities [11, 34]. It is also emphasized that BD contributes to the implementation of more effective activities, e.g. supply chain optimization, optimal pricing of products, more efficient selection of people to perform specific tasks and professions, minimization of making various mistakes, improving quality and improving customer relationships [7, 34]. Gunther et al. [20] state that the economic value of using BD can be measured by organizations in terms of profit, business expansion or competitive advantage. Other economic and social values resulting from BD analysis may be reflected in improving decision-making, streamlining business processes and creating innovative business models for e-commerce and, security [10, 33, 42], as well as the tracking and monitoring of various socioeconomic phenomena $[14,50,61]$. Some authors point to the value of $\mathrm{BD}$ in the context of contemporary environmental problems [1], sustainable development [5], the development of intelligent health care and smart cities [48, 62], as well as other issues related to the development of the world. At the same time, it is increasingly underlined that without an appropriate strategy in the organization aimed at proper BD management, achieving original values from BD resources can be difficult or even impossible [12, 22, 30, $34,43,50]$.

Himmi and others [22] proposed four strategies aimed at obtaining value from BD in organizations. They are referred to as: routine, integration, strategic and excellence. These strategies illustrate the relationship between operational activity, the dynamics of decision-making and the capability to analyze BD. The first strategy takes place when the operational activity in organizations is dominant and organizations have limited possibilities in accessing and analyzing large-data volumes. Data analysis takes place at a low level of processing and is limited to simple mathematical and logical procedures. The second strategy concerns the situation when organizations face 
the necessity of quick decision-making and dynamic reaction to changing business conditions. However, they have limited analytical capabilities. The combination of a high level of analytical capabilities with dynamic decisions is identified with the strategic approach and BD adoption to analyze the market, customers, competitors, etc. The last strategy means that organizations owe their competitive advantage and position on the market to the widespread use of BD.

Table 1: Strategies geared toward the BD development

\begin{tabular}{|l|l|l|}
\hline Strategies & $\begin{array}{l}\text { Description of } \\
\text { strategy }\end{array}$ & Authors \\
\hline $\begin{array}{l}\text { Strategy based on } \\
\text { the relationships } \\
\text { between } \\
\text { operational } \\
\text { activity, decision- } \\
\text { making dynamics } \\
\text { and the ability to } \\
\text { analyze data }\end{array}$ & $\begin{array}{l}\text { Strategic and } \\
\text { excellence }\end{array}$ & {$[22]$} \\
\hline $\begin{array}{l}\text { Strategy based on } \\
\text { relationships } \\
\text { between business } \\
\text { goals and the data } \\
\text { type and data } \\
\text { analysis }\end{array}$ & $\begin{array}{l}\text { Performance } \\
\text { management, data } \\
\text { exploration, social } \\
\text { analytics and decision } \\
\text { science }\end{array}$ & \\
\hline $\begin{array}{l}\text { Strategy based on } \\
\text { the development } \\
\text { of analytical skills }\end{array}$ & $\begin{array}{l}\text { There are three levels } \\
\text { of analytical } \\
\text { adaptation: } \\
\text { aspirational, } \\
\text { experimental and } \\
\text { transformational }\end{array}$ & {$[30]$} \\
$\begin{array}{l}\text { Limited analytics, } \\
\text { local analytics, } \\
\text { analytical aspirations, } \\
\text { analytical firms, } \\
\text { analytical } \\
\text { competition }\end{array}$ & {$\left[\begin{array}{l}\text { [12] } \\
\text { components }\end{array}\right.$} & \\
\hline $\begin{array}{l}\text { Strategy of } \\
\text { mampeting on the based on } \\
\text { analytical } \\
\text { capabilities }\end{array}$ & $\begin{array}{l}\text { Leadership, talent } \\
\text { management, } \\
\text { technologies, } \\
\text { decision-making and } \\
\text { organization's } \\
\text { structure }\end{array}$ & {$[34]$} \\
\hline
\end{tabular}

In turn, Parise et al. [43] distinguished four BD development strategies that refer to business goals, data type and conducted analyzes. They are defined as: performance management, data exploration, social analytics and decision science. Performance management refers mainly to the analysis of transactional data from corporate databases. The second strategy, "data exploration," is focused on the use of various statistical tools to analyze transactional data. Whereas the "social analytics" strategy enables advanced experimenting on data and answering questions about, among others, users' behaviors based on their previous transactions and preferences. The last strategy concerns experiments and analyzes of nontransactional data, such as, for example, surveys of users' opinions on social media about products. In contrast to the previous strategy - "social analytics," which focuses on the measurement of known goals, the "decision science" strategy is focused on conducting research and testing hypotheses.

According to LaValle and others [30], organizations that intend to benefit from BD should develop their analytical skills. There are three levels of analytical adaptation: aspirational, experimental and transformational. The first level means that organizations are focused on improving organizational efficiency, automating existing processes and are looking for ways to reduce the costs of running their business. The second level applies to organizations that have already acquired some analytical skills. Such organizations want their management to come out beyond cost optimization issues. They try to use the analytics to increase the efficiency of decision-making at all levels of management. The third level applies to those organizations that use their analytical experience to improve their competitiveness.

The model developed by [12] describes the path along which organizations should go to maturely compete in the market based on their analytical skills. The model includes five stages, defined as: limited analytics, local analytics, analytical aspirations, analytical companies, analytical competition. Organizations that belong to the first level do not have the analytical will nor skills. They struggle with human and technical problems and focus on the integrity of operational activities. Local analytics is a state in organizations when the first analytical work is undertaken, but it is closely related to the operational activity. Organizations from level three are becoming increasingly aware of the importance of analyzing data. They capture certain values from data analysis, but they are still far from competing on the basis of analytics. Organizations from the fourth stage, analytical companies, concentrate on making various analyzes that they use in decision-making. They have high analytical capabilities, but have not yet developed mechanisms for creating business value based on data analysis. The last level of the discussed model concerns an organization where analytics is the basic driver of creating new business value.

The conducted analysis of the literature allows to conclude that despite carrying out numerous studies on 
$\mathrm{BD}$, the problem of $\mathrm{BD}$-driven value creation is still poorly recognized. The focus of interest of many researchers is on analytical capabilities and the analytical maturity of the organization. So far, the mechanisms shaping value creation driven from BD resources and methods of measuring this value have not been studied in a comprehensive way. This situation prompts us to develop a comprehensive model of BDdriven value creation.

\section{Proposal of BD-driven value creation framework}

At the outset, it was assumed that the BD-driven value creation framework should enable the organization to go beyond traditional business functions and processes, facilitate the integration of internal and external processes, expand existing capabilities and skills, and transform the supply chain into a dynamic ecosystem. All these activities are based on digitization of information, advanced analytics and appropriate orchestration of BD resources. The proposed framework has three main constructs:

- organization's dynamic capabilities,

- integrated process of BD resource exploration and exploitation,

- value identification and measurement.

The dynamic capabilities of organizations that should contribute to creating, extending, protecting and maintaining a unique database are to be considered a key point in this model. Such a database should enable tracking both internal weaknesses and organization's opportunities as well as external conditions describing exogenous factors characterized by uncertainty and dynamism. According to Wang et al. [62], the organization's dynamic capabilities in the context of value creation are influenced by such resources as: information (rare, valuable, non-transferable), analytical skills, organizational and technical skills, and organizational culture aimed at acquiring, analyzing and using data. The capability to quickly acquire up-to-date, reliable and complete information, as well as the capability to integrate, reconfigure, analyze and interpret it appropriately is a critical success factor in creating value. Two analytical skills are particularly important in this context: the speed of insight into BD resources and the speed of its use to maximize value. Due to the type of data and the purpose of analysis, the analysis itself may be descriptive, predictive and prescriptive. It includes a set of aggregated techniques, analytical techniques, interpretation techniques that allow users to transform data into evidence-based decisions and take different actions. Such an analysis should contribute to the transformation of the organization, consisting of the transition from a retrospective analysis to a predictive and real-time analysis $[12,43,50]$. The capability to think strategically, i.e. to understand business and modern ICT, the capability to manage change, risk and responsibility, is very important here. The research conducted by [34] showed that organizations which succeeded in using BD had clearly defined goals and defined measures of success. Leaders of such organizations perfectly understood the mechanisms of functioning of markets, they thought creatively and were focused on creating an innovative market offer. Knowledge of business problems, working with the right data, as well as knowledge of problem solving techniques, together constitute the instrumentation that contributes to the creation of business value.

The second component plays an important role in the proposed model. It is an integrated process of BD resource exploration and exploitation, leading to the creation of unique values in organizations. Exploitation is related to the use of the already existing organizational knowledge base [29, 32]. Therefore, as long as the organization undertakes activities in which it uses its competences, that long they are aimed at exploitation. Exploitation is limited to the local exploitation of information resources and their internal integration. Local exploitation may relate to any activity consisting in redesigning existing business functions and operations. Internal integration is used to create unified business processes that reflect technological and organizational connections [62].

In turn, BD resource exploration is associated with exceeding the boundaries of the organization's current knowledge base and skills $[29,32]$. It can lead to new technical skills, market experiences and new relationships with the environment. Exploration is therefore a conscious search for new sources of knowledge, enrichment of resources, adopting new cognitive orientations and acquiring new competences. According to Wang and others [62], BD resource exploration may be focused on: (1) redesigning business processes, (2) redesigning business networks, and (3) completely redefining a business area. Redesigning business processes involves redesigning key processes to achieve new organizational capabilities to compete in the future. In turn, redesigning the business network means involving new participants in the business network to deliver new products and services to the market. Redefinition of the business area, refers to those business practices that, for example, change the current corporate order. It is required here, not only to use advanced analytical tools, but also integrated digital platforms, such as Hadoop. It seems that a beneficial solution for the organization is a skilful combination of activities related to both exploration and exploitation of $\mathrm{BD}$ resources [57]. An important role here should be 
played by "data scientists" and other highly qualified employees who are able to work with huge volumes of data. It is them who should outline the vision of using analytical tools for BD exploration and its value [34].

The third proposed construct is that all activities are aimed at identifying and measuring values resulting from $\mathrm{BD}$ use. The ability to recognize opportunities and chances on the market, understanding business and ICT, as well as the absorption and analytical capabilities of the company should transform into tangible results. They can be seen in [3]: (1) the use of a variety of information and its extensive digitization, (2) the use of multilateral business models, (3) model coordination in networks, and (4) network architecture control. Referring to the first element, it is worth noting that the increase in value can take place through the very fact of unlimited access to various information resources [41]. This is becoming important today, especially in the context of the need to quickly satisfy the needs of customers. BD technology gives the possibility to increase the availability of data placed on blogs, social networks as well as its effective processing and analysis. An increasing number of companies personalize their offer based on information collected, for example, on Facebook. It is easier to share information and redistribute information. More and more companies are also building their competitive advantage on advanced equipment, specialized software and applications as well as on Internet communication. Creating value using $\mathrm{BD}$ can also be done through multilateral business models. Delivery of specific products and services is increasingly often done in close cooperation with other companies, e.g. telecommunications operators, companies from the financial sector. Through BD platforms, businesses can operate more efficiently and optimize their supply chain and manage their innovation. A logical extension of multilateral business models is complex, dynamic coordination within many companies. Thanks to advanced BD platforms and hardware, there may be a breakdown of traditional sectoral barriers and the possibility of companies operating in a new space and market niches [9]. Companies can cooperate closely together, co-create a shared value in networks and share that value. It is also worth emphasizing that companies can benefit not only from their innovative products, but also from the original partnership and impact of ICT, both on a single company and the entire industry.

According to Shang and Seddon [52], the obtained values (benefits) can be classified into five dimensions: (1) ICT infrastructure (e.g. more flexible ICT infrastructure, reduction of ICT costs, increase in ICT infrastructure performance), (2) operational (e.g. cost reduction, improvement of efficiency, improvement of quality, improvement of customer service), managerial (e.g. better management of resources, improvement of decision-making and planning, efficiency improvement), (4) strategic (e.g. supporting alliances, developing innovative business, product differentiation, creating business networks), and (5) organizational (e.g. changing work patterns, improving organizational learning). At this point, it should be emphasized that organizational learning is important in identifying BD benefits, meaning the organization's ability to quickly recognize the unique values of new information, assimilation and application, as well as reconfiguration and integration of existing information. What is also important here is the ability to exchange knowledge, share knowledge and expertise among various people.

\section{Verification of the developed framework in the light of own empirical research}

The proposed framework of BD-driven value creation has been subjected to initial empirical verification. The survey was conducted among 25 Polish organizations using the method of in-depth interview in 2015. The surveyed enterprises represented the services (10), production (9) and sales (6) sector. The respondents were primarily representatives of management and ICT specialists. The questions focused on three main issues: (1) organization's dynamic capabilities, (2) organizational activity and creation leading to changes in organizations (e.g. new business models), (3) assessment and measurement of benefits from the use of information resources, including BD.

\subsection{Organization's dynamic capabilities}

Most of the surveyed organizations identified their dynamic capabilities with dynamic analytical capabilities and the use of various ICT tools. The respondents stressed that modern ICT allow them to better organize, analyze and use $\mathrm{BD}$ resources and utilize them to create a competitive advantage. They have seen great potential in BD resources, although they were also aware of various threats and barriers. Attention was drawn, among others, to the necessity of constant learning, up-skilling in conducting various analyzes, and, above all, in their interpretation. Unfortunately, all the surveyed organizations emphasized that they do not have enough employees with good analytical skills and the ability to think creatively that can lead to the development of original business models. The respondents pointed to the huge role of senior management staff, who should show interest in analyzing and using BD in decision-making (18 indications). The need for more creative and original work of managers of individual departments (14 indications), employee groups (12 responses), ICT 
specialists (11 indications), employees (10 indications), analysts (10 indications) and project teams (7 indications) was also emphasized.

Regrettably, research has shown that most organizations use rather simple ICT tools to analyze their information resources, including BD. Most often mentioned were: tools for searching information on the Internet (22 organizations), spreadsheets and databases (18 organizations), tools for internal integration of business processes and document management (15 organizations), tools for data visualization (13 organizations). Definitely less often organizations used such solutions as: BI (10 responses), supply chain integration tools (10 responses), CRM tools (9 responses), group work systems (8 responses), Expert Systems (6 responses), discussion forums (6 responses), complex computer simulations (5 responses), specialized BD processing tools (5 responses), DSS (4 responses). The respondents, when asked about the reasons for using rather simple ICT tools in their activity, indicated lack of sufficient knowledge about the possibilities offered by various ICT tools and lack of sufficient skills to use them (11 responses), lack of time to learn about new tools (11 responses), lack of personalized tools ICT (11 responses) and lack of sufficient motivation to use more complex data analysis tools.

\subsection{The integrated process of $\mathrm{BD}$ resource exploration and exploitation aimed at value creation}

Another set of questions was aimed at identifying the actions that are taken in organizations that lead to any changes, transformations and development of new business models using ICT and BD. The research has shown that most organizations, all the time, pay great attention to the management of internal resources and internal business processes. Analyzing external sources of information comes down to simple functions of searching, sorting and aggregating data, e.g. tracking customers' interest in products of a given company and tracking the impact of advertising on the increase in purchases of selected products and services. Only five organizations confirmed that they systematically analyze Internet resources, conduct basket, loyalty and customer segmentation analyzes. On their basis, organizations create personalized business offers, dedicated advertising spots, reach their clients in a personalized way and predict their loyalty. It is worth emphasizing that these organizations are open to entering into different alliances, entering into various configurations of supply chains, constantly looking for new suppliers and partners, and expanding their business activities with new segments (e.g. financial services). At the same time, these organizations emphasized that they are not afraid of change, on the contrary, they recognize that no change is a warning signal of impending stagnation.

Most organizations have assessed their knowledge about BD exploration and exploitation rather as an average. The representatives of only eight organizations claimed to be sufficiently prepared to create BD-driven new models and e-services. In six organizations, the level of knowledge and skills in this area was assessed as far from satisfactory and allowing the development of BD-driven original business solutions. In other organizations, this level was considered as average and probably not giving rise to new business activities. The study showed that most organizations do not think about information resources, including BD resources, in terms of strategic resources. Unfortunately, only five of the surveyed organizations admitted that the conducted analyzes are purely exploratory in nature. The vast majority of conducted analyzes are operational analyzes.

The survey clearly indicated that most organizations do not have consistent, comprehensive strategies and business practices focused on BD exploration and exploitation. Organizations do not carry out professional analyzes on the needs of BD analysis, they do not also know who should be responsible for exploring BD, developing strategies for using BD resources as well as taking care of security issues and $\mathrm{BD}$ resource protection. Only some departments in the surveyed organizations developed BD exploration strategies on their own (e.g. sales and marketing departments). The research demonstrated that the majority of the surveyed organizations are not aware of the importance and need to develop such a BD exploration strategy. Only two organizations (from the service sector) noticed having a coherent overall strategy of BD, related to the business strategy. In seven organizations, such strategies were developed for specific departments. Other organizations did not have such strategies. The study showed a strong correlation between having a BD exploration strategy and organizational culture. The organizations with good leadership, open to new products, changes and innovation were vitally interested in competing on the basis of information and intellectual resources.

\subsection{BD-driven value identification and measurement}

The interviews of the respondents show that organizations have a relatively high awareness of potential values resulting from $\mathrm{BD}$ exploration and adoption. Unfortunately, they are not always able to precisely quantify these values. This is evidenced by selected respondents' comments on BD. For example: "(1) thanks to BD, we create a new, valuable database 
about customers, suppliers and other market partners; (2) information resources are our strategic resource that enable us to solve many complex economic problems resulting from economic, ecological and demographic crises; (3) information resources play a more important role for us than effective production systems; (4) BD is for us the factor of effective organizational development, gaining competitive advantage and staying in an ever-changing environment; (5) BD is helpful in building innovative business models; (6) we base our business on BD, Internet tracking, social media; (7) advanced analytics and ICT tools allow us to discover new business value from BD resources."

The in-depth interviews with respondents confirmed that the most values from BD adoption were identified in the area of operational and managerial activities (21 indications). In the area of managerial activity, the following were mainly mentioned: better monitoring of sales, more effective management of customer relations, reduction of sales and service costs, improvement of payments, reduction of delivery time, reduction of the number of complaints. In the area of managerial activity, first of all, the following were distinguished (20 indications): more effective decision-making (factbased decisions), shortening decision-making time, more effective planning. Five of the surveyed organizations also indicated the strategic management value from $\mathrm{BD}$ processing. In particular, they mentioned: faster establishing of contacts with customers and suppliers, faster learning about customer preferences and market trends, reducing the risk of investing in new products and services, and more efficient supply chain management. All organizations agreed that $\mathrm{BD}$ exploration brings organizational benefits which are manifested, among others, in the development of a new work culture, focused on data transparency, high quality of data, learning, mobility and changes. Nearly half of the surveyed organizations declared that they had professional databases, repositories and warehouses, storing historical data about customers, suppliers and competitors. Such repositories were considered by the respondents to be a significant value driven from BD exploration.

\section{Conclusions}

Although $\mathrm{BD}$ has recently become an interesting area of scientific discourse, there is still a lack of comprehensive research devoted to the problem of BDdriven value creation. This study brings a significant contribution to the development of research into BD management. It broadened knowledge about the specificity of BD resources and mechanisms that influence the creation of value in organizations. The research resulted in the proposal to outline a BD-driven value creation framework in organizations. The framework distinguishes three main constructs: the organization's dynamic capabilities, the integrated process of BD resource exploration and exploitation as well as the identification and measurement of value. This study also makes an important contribution to business practice. The developed model has been subject to initial verification. This verification was carried out in selected organizations using an in-depth interview method. The conclusions from the conducted research may prove to be helpful for all organizations that intend to use BD resources in their activities.

The conducted research, both the literature and own empirical research, confirm our conviction that we need to conduct further work on learning about the mechanisms of extracting value from BD. Recognition of such value creation mechanisms in various corporations and employee groups seems particularly important. It would also be advisable to conduct empirical research on a larger sample (number) of organizations and comparative analyzes, e.g. due to the different organizational culture, size of the organization and relationships with the environment.

\section{References}

[1] An Q., Wen Y., Xiong B., Yang M., and Chen X. (2017), "Allocation of carbon dioxide emission permits with the minimum cost for Chinese provinces in big data environment", Journal of Clear Production, Vol. 142, pp. 889-893.

[2] Arora, A., and Nandkumar, A. (2012), "Insecure advantage? Markets for technology and the value of resources for entrepreneurial ventures", Strategic Management Journal, Vol. 33, pp. 231-251.

[3] Bhardawaj, A.S. (2000), "A Resource-Based Perspective on Information Technology Capability and Firm Performance: An Empirical Investigation", MIS Quarterly, Vol. 24, No. 1, pp. 169-196.

[4] Bharadwaj, A., El Sawy, O.A., Pavlou, P. A., and Venkatraman, N. (2013), "Digital Business Strategy: Toward a Next Generation of Insights", MIS Quarterly, No. 37(2), Special Issue: Digital Business Strategy, pp. 471-482.

[5] Bibri, S., and Krogstie, J. (2017), "ICT of the new wave of computing for sustainable urban forms: Their big data and context-aware augmented typologies and design concepts", Sustainable Cities and Society, Vol. 32, pp. 449-474.

[6] Chen, C., and Zhang, C.Y. (2014), "Data-intensive applications, challenges, techniques and technologies: A survey on big data", Information Science, Vol. 275, pp. 314-347.

[7] Chen, H., Chiang, R.H.L., and Storey, V.C. (2012), "Business Intelligence and analytics: from Big data to big impact”, MIS Quarterly, No. 36, No. 4, pp. 1-24.

[8] Chen, M., Mao, S., and Liu, Y. (2014), "Big data: a survey”, Mobile Networks and Applications, Vol. 19, No. 2, pp. 171-209. 
[9] D'Adderio, L. (2001), "Crafting the Virtual Prototype How Firms Integrate Knowledge and Capabilities cross Organizational Boundaries", Research Policy, No. 30(9), pp. 1409-1424.

[10] Das, T. K., and Kumar, P. M. (2013), "Big data analytics: a framework for unstructured data analysis", International Journal of Engineering Science \& Technology, Vol. 5, No. 1, pp.153.

[11] Davenport, T., Barth, P., and Bean, R. (2012), "How big data is different", MIT Sloan Management Review, Vol. 54, No. 1.

[12] Davenport, T.H., and Harris, J.G. (2007), Competing on Analytics. The New Science on Winning, Boston Massachusetts, MA: Harvard Business School Press.

[13] Drucker, P. (2014), Innovation and entrepreneurship, Routledge, New York.

[14] Erickson, G., and Rothberg, H. (2013), Competitors, Intelligence, and Big Data, in: J. Liebowitz (eds), Big Data and Business Analytics, Boca Raton: CRC Press, Taylor \& Francis Group, LLC, pp. 103-115.

[15] Erl, T., Khattak, W., and Buhler, P. (2015), Big Data Fundamentals: Concepts, Drivers \& Techniques. Boston: Prentice Hall.

[16] Feeny D.F., and Willcocoks L.P. (1998), "Core IS capabilities for Exploiting Information Technology", Sloan Management Review, Vol. 39, No. 3, pp. 9-21.

[17] Fink, L, Yogew, N., and Even A. (2017), "Business intelligence and organizational learning: An empirical investigation of value creation process", Information \& Management, Vol. 54, pp. 38-56.

[18] George, G., Haas, M.R., and Pentland, A. (2014), "Big data and Management" Academy of Management Journal, Vol. 57, No. 2, pp. 321-326.

[19] Goes, P.B. (2014), "Big Data and IS Research:, MIS Quarterly, Vol. 38, No. 3, pp. iii-viii.

[20] Gunther, W.A., Mehrizi, R.H. R., Huysman, M., and Feldberg, F. (2017), "Debating big data: A literature review on realizing value from big data', Journal of Strategic Information Systems, No. 26, pp. 191-209.

[21] Hagen, C., Khan, K., Ciobo, M., Miller, J., Wall, D., Evans, H., and Yadav, A. (2013), "Big data and the Creative Destruction of Today's Business Models", ATKerney, retrieved from https://www.atkearney.de/documents/10192/698536/Bi $\mathrm{g}+$ Data+and+the+Creative+Destruction + of + Todays $+\mathrm{B}$ usiness+Models.pdf/f05aed38-6c26-431d-8500d75a2c384919.

[22] Himmi, K. Arcondara, J., Guan, P., and Zhou, W. (2017), "Value oriented Big data strategy: analysis \& case study", Proceedings of $50^{\text {th }}$ Hawaii International Conference on System Sciences.

[23] Hsu, D.H., and Ziedonis, R.H. (2013), "Resource as dual sources of advantage: Implications for valuing entrepreneurial - firm patents" ,Strategic Management Journal, Vol. 34, pp. 761-781.

[24] Iafrate, F. (2014), "A Journey from Big Data to Smart Data. Digital Enterprise Design \& Management", Advances in Intelligent Systems and Computing, Vol. 261, pp. 25-33.

[25] IBM (2012), "IBM Big data: A collection of Big Data client success stories", retrieved from ftp://ftp.software.ibm.com/software/data/swlibrary/big-data/ibm-big-datasuccess.pdf.

[26] Ishikawa, A., and Nakagawa, J. (2013), An Introduction to Knowledge Information Strategy. From Business Intelligence to Knowledge Sciences, London: World Scientific.

[27] Kaisler, S., Aromour, F., Epinosa, A., and Money, W. (2013), "Big Data: issues and challenges moving forward", Proceedings of $46^{\text {th }}$ Hawaii International Conference on System Science, pp. 995-1004.

[28] Kohli R., and Grover V. (2008), "Business Value of IT: An Essay on Expanding Research Directions to Keep up with the Times", Journal of Association for Information Systems, No. 9(1), pp. 23-39.

[29] Lavie, D., Stettner, U., and Tushman, M.L. (2010), "Exploration and Exploitation Within and Across Organizations", The Academy of Management Annals, Vol. 4, No. 1, pp. 109-155.

[30] LaValle, S., Lesser, E., Shockley, R., Hopkins, M., and Kruschwitz, N. (2011), "Big data, analytics and the path from insigths to value" MIT Sloan Management Review, Vol. 52, No. 2, pp. 21-31.

[31] Leney, D., and Taylor, P., (2013), Big data means big business, Gartner INC.

[32] Levinthal, D.A., and March, J.G. (1993), "The Myopia of Learning”. Strategic Management Journal, Special Issue, Vol. 14, pp. 95-112.

[33] Manyika, J., Chui, M., Brown, B., Bughin, J., Dobbs, R., Roxburgh, C., and Byers, A. H. (2011), Big data: The next frontier for innovation, competition, and productivity, KY: McKinsey Global Institute.

[34] McAfee, A., and Brynjolfsson, E. (2012), "Big data: The management revolution", Harvard Business Review, October 2012, pp. 59-69.

[35] Microsoft (2016), Microsoft Analytics Platform System, retrieved from https://www.microsoft.com/en-us/servercloud/products/analyticsplatformhttps://www.microsoft.com/en-us/servercloud/products/analytics-platformsystem/overview.aspxsystem/overview.aspx.

[36] Mitchell, W.J., and Inouye, A.S., Blumenthal M.S.(2003), Beyond Productivity: Information Technology, Innovation and Creativity. Technology and Creativity, National Research Council, National Academy of Science, Washington, 2003.

[37] Nonaka, I., and Takeuchi, H.(1995), The knowledgecreating company, University Press, Oxford.

[38] Nunamaker, J.F., Chen, M., and Purdin, T.D.M. (1991), "Systems development in Information Systems Research", Journal of Management IS, Vol. 7, No. 3, pp. 89-106.

[39] Olszak, C. M. (2016), "Toward better understanding and use of Business Intelligence in organizations", Information Systems Management, Taylor \& Francis, Vol. 33, No. 2, pp. 105-123.

[40] Olszak, C.M., Bartuś, T., and Lorek, P. (2018), “A Comprehensive Framework of Information System Design to Provide Organizational Creativity Support", Information \& Management, Elsevier, No. 55, pp. 94108. 
[41] Olszak, C.M., and Kisielnicki, J. (2018), “A conceptual framework of information systems for organizational creativity support. lessons from empirical investigations", Information Systems Management, Taylor \& Francis, Vol. 35, No. 1, pp. 29-48.

[42] O'Driscoll, T. (2014), "Can big Data deliver added value", Tranining, Vol. 51, No. 2, pp. 51.

[43] Parise, S., Iyer, B., and Vesset, D. (2012), "Four strategies to capture and crate value from big data", Ivey Business Journal, Issues July, 2012, retrieved August 3, 2017 from http://iveybusinessjournal.com/publication/fourstrategies-to-capture-and-

createhttp://iveybusinessjournal.com/publication/fourstrategies-to-capture-and-create-value-from-bigdata/value-from-big-data/

[44] Peteraf, M.A. (1993), "The Cornerstones of Competitive Advantage: A Resource-Based View", Strategic Management Journal, Vol. 14, pp. 179-191.

[45] Ransbotham, S., Kiron, D., and Prentice, P.K. (2016), "Beyond the hype: the hard work behind analytics success", MIT Sloan Maange Rev., Vol. 57, No. 3, pp. 3-16.

[46] Rising, C.J, Kristensen, M., and Tjerrild- Hansen, S. (2014), Is Big Data too Big for SMEs? Leading Trends in Information Technology, Stanford: Stanford University.

[47] Ross, J., Beath, C.M., and Goodhue, D.L (1996), "Develop Long-term Competitiveness trough IT assets", Sloan Management Review, Vol. 39, No. 1, pp. 31-42.

[48] Sampri, A., Mavragani, A., and Tsagarakis, K. (2016), "Evaluaing Google trends as a tool for integrating the smart health concept in the smart cities governance in USA", Proccedia Engineering, Vol. 162, pp. 585-592.

[49] Schick, A., Frolick, M., and Ariyachandra, T. (2011), "Competing with BI and Analytics at Monster Worldwide', Proceedings of the 44 Hawaii International Conference on System Sciences, Hawaii.

[50] Schmarzo, B. (2013), Big Data: Understanding How Data Powers Big Business, Indianapolis: John Wiley and Sons.

[51] Sirmon, D.G., Hitt, M.A., Ireland, R.D., and Gilbert, B.A. (2011), "Resource orchestration to create competitive advantage: Breadth, depth, and life cycle effects", Journal of Management, Vol. 37, pp. 13901412.

[52] Shang, S., and Seddon, P.B. (2002), "Assessing and managing the benefits of enterprise systems: the business manager's perspective", Information Systems Journal, Vol. 12, No. 4, pp. 271-299.

[53] Steiger, D.M. (2010), "Decision Support as knowledge creation. A Business Intelligence Design Theory", International Journal of Business Intelligence Research, Vol. 1, No. 1, pp. 29-47.

[54] Teece, D.J. (2010), "Business models, business strategy and innovation”, Long Range Planning, No. 43, pp. 172194.

[55] Teece, D.J., Pisano, G., and Shuen, A. (1997), "Dynamic capabilities and strategic management", Strategic Management Journal, Vol. 18, pp. 509-533.
[56] The Data Warehousing Institute (2013). TDWI Launches Big Data Maturity Model Assessment Too, retrieved from http://tdwi.org/Articles/2013/11/20/TDWI-Launches-

Big-Data-Maturity-Model-Assessment-

Tool.aspx ?Page $=2$.

[57] Tushman, M.L., and O'Reilly, C.A. (2004), "Ambidextrous Organization" Harvard Business Review, 82, April 2004, pp. 74-81, retrieved from http://hbr.org/product/ambidextrousorganization/an/R0404D-PDF-ENG.

[58] Ularu, E. G., Apostu A., Puican, F.C, and Velicanum, M (2012), "Perspectives on Big data and Big data analytics", Database Systems Journal, III, 4.

[59] Wade, M., and Hulland, J. (2004), "Review: The Resource-Based View and Information Systems research: Review, Extension, and Suggestions for Future Research", MIS Quarterly, Vol. 28, No. 1, pp. 107-142.

[60] Wales, W.J., Patel, P.C., and Kreiser, P.M. (2013), "Nonlinear effects of entrepreneurial orientation on small firm performance: the moderating role of resource orchestration capabilities",Strategic Entrepreneurship Journal, Vol. 7, pp. 93-121.

[61] Wamba, S., Akter, S., Edwards, A., Chopin, G., and Gnanzou, D. (2015), "How big data can make big impact: findings from a systematic review and a longitudinal case study", International Journal of Production Economics, Vol. 165, pp. 234-246.

[62] Wang, Y., Kung, L., Wang, W.Y.C., and Cegielski, C.C. (2018), "An integrated big data analytics-enabled transformation model: application to health care", Information and Management, No. 55, pp. 64-79.

[63] Webster, J., and Watson, R.T. (2002), "Analyzing the past to prepare for the future: Writing a literature review", MIS Quarterly, Vol. 26, No. 2, pp. XIII-XXIII.

[64] Zahra, S.A., Sapienza, H.J., and Davidsson, P. (2006), "Entrepreneurship and dynamic capabilities: A review, model, and research agenda", Journal of Management Studies, Vol. 43, pp. 917-955. 